\title{
Modeling and Parameter Extraction of PV Modules Using Genetic Algorithms and Differential Evaluation
}

\author{
Mr. G. Venkateswarlu ${ }^{1}$, Dr.P Sangameswar Raju ${ }^{2}$ \\ ${ }^{1}$ Prof in dept of EEE, Narayana Engg College, Nellore, gaddam. \\ ${ }^{2}$ Professor, S.V.Univesity, Tirupati.
}

\begin{abstract}
In this paper, represents a mathematical model with 7 parameters. Calculating fitness requires simulation on this model. To do this a MATLAB-Simulink model was developed. All calculations associated to process the genetic algorithms are integrated into one program, with very good convergence. In this paper a technique based on genetic algorithms is proposed for improving the accuracy of solar cell parameters extracted using conventional techniques. The approach is based on formulating the parameter extraction as a search and optimization problem. Current-voltage data used were generated by simulating a two-diode solar cell model of specified parameters. The genetic algorithm and differential evaluation algorithm search range that simulates the error in the extracted parameters was varied from \pm 5 to $\pm 100 \%$ of the specified parameter values. Results obtained show that for a simulated error of $\pm 5 \%$ in the solar cell model values, the deviation of the extracted parameters varied from 0.1 to $1 \%$ of the specified values.
\end{abstract}

Keywords: genetic algorithms, differential evaluation algorithm parameter extraction, photovoltaic's, solar cell matlab/simulink

\section{Introduction}

Advance of photovoltaic (PV) technology in recent years has made solar energy one of the key alternative energy sources available in the energy market. In order to make the PV energy more affordable, improvement on power efficiency of PV systems has recently been one of the major focuses in thePV research community and industry .

PV module represents the fundamental power conversion unit of a PV generator system. The output characteristics of PV module depends on the solar insolation, the cell Temperature and output voltage of PV module. Since PV module has nonlinear characteristics, it is necessary to model it for the design and simulation of maximum power point tracking (MPPT) for PV system applications. The mathematical PV models used in computer simulation have been built for over the pass four decades [1]-[3]. Almost all well-developed PV models describe the output characteristics mainly affected by the solar insolation, cell temperature, and load voltage. However, the equivalent circuit models are implemented on simulation platforms of power electronics, such as SPICE. Recently, a number of powerful component-based electronics simulation software package have become popular in the design and development of power electronics applications. However, the Sim Power System tool in Matlab/Simulink package offers wind turbine models but no PV model to integrate with current electronics simulation technology. Thus, it is difficult to simulate and analyze in the generic modeling of PV power system. This motivates me to develop a generalized model for PV cell, module, and array using Matlab/Simulink. Solar cell and panel circuit parameters are conventionally extracted from either the load I-V and P-V data measured under illumination or in the dark. Several methods for solar cell parameter extraction using the $\mathrm{I}-\mathrm{V}$ and $\mathrm{P}-\mathrm{V}$ characteristics have been proposed [1-11]. The direct approaches are based on the use of the I-V and P-V curve features such as the axis intercepts and the gradients at selected points to determine some of the cell parameters. The accuracy of these techniques is therefore limited by the the other approaches for parameter extraction realy on the use of fitting algorithms to determine the solar cell parameters. Their accuracy depends on the applied fitting algorithm, the user defined error function and the starting values of the parameters to be fitted [1].In this context, we propose a novel technique based on genetic algorithms for improving the accuracy of solar cell parameters extracted using direct techniques. The underlying concept is to formulate the solar cell parameter extraction as a search and optimization problem for a two-diode model. The application of this technique in practice would entail using one of the existing techniques to determine approximate starting values for these parameters. The proposed genetic algorithm method may then be used to refine these values.

\section{Review Of The Two-Diode Model}

2.1 Applications for crystalline Si dominate literature the two-diode model has primarily been applied to Mono crystalline-Si PV cells [2-8], as this technology dominated the market for the initial half century of the modern photovoltaic age $[9,10]$. There are few reports on the application of the model for polycrystalline 
cells.However, due to its lower production cost, polycrystalline-Si has recently gained market share similar to mono crystalline-Si. Therefore, it is important to study the applicability of the two-diode module for polycrystalline-Si cells as well. The lumped circuit model The two-diode, lumped-circuit model of a PV cell is shown in Fig. 1. The mathematical form of the model is given by Eq. (5).

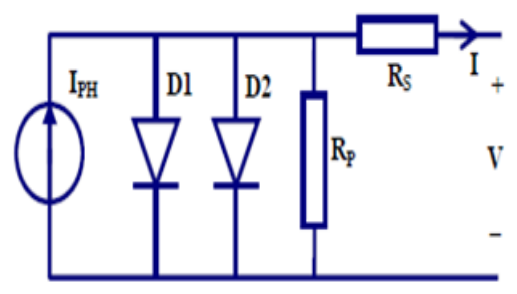

Figure 1: Lumped-circuit, two-diode model of a PV cell.

The terminal current I of the cell can be divided into four components, as shown in Eq. (5): the photo generated current $\left(\mathrm{I}_{\mathrm{PH}}\right)$, the current through the shunt resistance $\left(\mathrm{I}_{\mathrm{P}}\right)$, the diffusion-diode current $\left(\mathrm{I}_{\mathrm{D} 1}\right)$, and the recombination-diode current $\left(\mathrm{I}_{\mathrm{D} 2}\right)$. The 7unknown parameters in the model are: the photo generated current IPH; the series resistance RS; the shunt (or parallel) resistance RP; the reverse saturation current $\mathrm{I}_{01}$ and the ideality factor $\mathrm{n} 1$ of the diffusion diode; and the reverse saturation current $I_{02}$ and the ideality factor $n 2$ of the recombination diode. $\mathrm{n} 1$ is oft- en assumed to be equal to 1 by many authors, in accordance with the diffusion theory of $\mathrm{p}-\mathrm{n}$ junctions [11], where as $\mathrm{n}_{2}$ is sometimes set equal to 2, in accordance with the theory of recombination via traps [12]. The thermal voltage $\mathrm{VT}=\mathrm{kBT} / \mathrm{qe}$, where $\mathrm{T}$ is the $\mathrm{p}-\mathrm{n}$ junction temperature (considered to be a known or controlled quantity), $\mathrm{kB}$ is Boltzmann's constant, and qe is the elementary charge .The parameters in the two-diode model depend on the irradiance and cell temperature $[6,7,8]$.

With reference to figure 1 , the current-voltage relation of a twodiodemodel for a silicon solar cell may be expressed as [12]

$\mathrm{I}_{\mathrm{L}}=-\mathrm{I}_{\mathrm{ph}}+\mathrm{I}_{\mathrm{D} 1}+\mathrm{I}_{\mathrm{D} 2}+\mathrm{I}_{\mathrm{sh}}$

where $I_{\text {ph }}$ is the cell-generated photocurrent,

$\mathrm{I}_{\mathrm{D} 1}=\mathrm{I}_{\mathrm{SD} 1}\left[\exp \left(\mathrm{q}\left(\mathrm{V}_{\mathrm{L}}-\mathrm{I}_{\mathrm{L}} \mathrm{Rs}\right) / \mathrm{n}_{1} \mathrm{~K}_{\mathrm{t}}\right)\right]-1$
$\mathrm{I}_{\mathrm{D} 2}=\mathrm{I}_{\mathrm{SD} 2}\left[\exp \_\left(\mathrm{q}\left(\mathrm{V}_{\mathrm{L}}-\mathrm{I}_{\mathrm{L}} \mathrm{Rs}\right) / \mathrm{n}_{2} \mathrm{k}_{\mathrm{T}}\right)\right]-1$

And

$I_{s h}=V_{L}-I_{L} R s / R_{s h}$

$\mathrm{I}(\mathrm{V})=\mathrm{I}_{\mathrm{PH}}-\mathrm{I}_{\mathrm{P}}-\mathrm{I}_{\mathrm{D} 1}-\mathrm{I}_{\mathrm{D} 2}=\mathrm{I}_{\mathrm{PH}} \ldots \mathrm{V}+\mathrm{I} \mathrm{R}_{\mathrm{S} / \mathrm{RP}} \mathrm{I}_{\mathrm{O} 1}\left[\exp ^{\mathrm{V}+\mathrm{I} \mathrm{R}_{\mathrm{S}} / \mathbf{n}} \mathbf{V r} \ldots\right]_{-}$

$$
\mathrm{I}_{\mathrm{O} 2}\left[\exp _{\mathrm{V}}^{+\mathrm{IR}} \mathrm{S}_{1} / \mathbf{n} \mathbf{V r}^{-1}\right]
$$

In the equations above, Rs and Rsh are the series and shunt resistances respectively, $\mathrm{I}_{\mathrm{SD} 1}$ and $\mathrm{I}_{\mathrm{SD} 2}$ are the diffusion and saturation currents respectively, $\mathrm{n}_{1}$ and $\mathrm{n}_{2}$ are the diffusion and recombination diode ideality factors, $\mathrm{k}$ is Boltzmann's constant, $\mathrm{q}$ is the electronic charge and $\mathrm{T}$ is the temperature in kelvin. From the above equations, it is seen that the solar cell parameter extraction problem reduces to determination of the seven parameters (Rs , Rsh, Iph, I $\mathrm{I}_{\mathrm{SD} 1}, \mathrm{I}_{\mathrm{SD} 2}, \mathrm{n}_{1}$ and $\mathrm{n}_{2}$ )from the $\mathrm{I}-\mathrm{V}$ characteristics. In this paper, this process is formulated, using genetic algorithms, as a search and optimization procedure as discussed below.

\section{Pv Model Building And Simulation}

A model of PV module with moderate complexity which includes the temperature independence of the photocurrent source, the saturation current of the diode, and a series resistance is considered based on the Shockley diode equation. It is important to build a generalized model suitable for all of the PV cell, module, and array, which is used to design and analyze a maximum power point tracker. Bing illuminated with radiation of sunlight, PV cell converts part of the photovoltaic potential directly into electricity with both I-V and P-V output characteristics. A generalized PV model is built using Matlab/Simulink [13] to illustrate and verify the nonlinear I-V and P-V output characteristics of PV module.The proposed model is implemented and shown in Figs. 2 . 


\section{Genetic algorithms}

Genetic algorithms (GAs) are a subclass of what are known as evolutionary algorithms [13]. These are computational models that mimic natural evolution in their design and implementation; i.e. they are based on survival of the fittest. GAs differ from conventional search techniques in that they operate on a coded parameter set of the solution, are global in their search, make use of a cost function that does not involve derivatives and finally employ pseudo-probabilistic rules and not deterministic ones.

\section{Differential Evolution}

Differential Evolution is an evolutionary strategy. It performs optimization by simulating evolution in the nature. Optimization starts by generating initial population members. The best offspring of actual generation form the next generation. Each new population member inherits properties of his parents. The population size is constant while the objective function evaluates quality of each individual in the population. Only the best members survive. In this way, the best properties inherit from generation to generation, leading to the population members with the best properties at the end of optimization. In the given case, the operational diagrams of hydrogen production unit and fuel cell unit are to be determined by the optimization for 24 hours long interval of observation. Considering 15 minutes long discrete time intervals, both of them are given in 96 points. In the sense of Differential Evolution, each population member is a vector consisting of 192 elements, 96 for the hydrogen production unit operational diagram and the other 96 for the fuel cell unit operational diagram. In order to determine both operational diagrams by

Differential Evolution an objective function $q$ is defined by (18) $: q=\mathbf{e} T \mathbf{e}$ (18)

where $\mathbf{e}$ is the vector of differences between produced power and the load demanded power given in 96 point for 24 hours.

\section{Extraction of solar cell parameters}

Generally, there are two possible approaches to extract the solar module parameters: the analytical and numerical extraction techniques .The former requires information on several key points of the $\mathrm{I}-\mathrm{V}$ characteristic curve, i.e. the current and voltage at the maximum power point (MPP), short-circuit current (ISC), open-circuit voltage (VOC), and slopes of the I-V characteristic at the axis intersections.The numerical extraction technique is based on certain mathematical algorithm to fit all the points on the $\mathrm{I}-\mathrm{V}$ curve. More accurate results can be obtained because all the points on the I-V curve are utilized . Evolutionary Algorithms (EAs) appear to be a natural choice to extract the module parameters at conditions other than STC. Due to the fact that the objective function in the extraction process tendto be multi-modal, EA methods can be very effective regardless of gradient and initial condition information Evolutionary Algorithms (EAs) appear to be a natural choice to extract the module parameters at conditions other than STC. Due to the fact that the objective function in the extraction process tend to be multi-modal, EA methods can be very effective regardless of gradient and initial condition information. In our work we propose Differential evolution and Genetic based methods for extraction of PV cell parameters

\subsection{The objective function}

$$
\begin{aligned}
\boldsymbol{J}= & \sqrt{\frac{\mathbf{1}}{\boldsymbol{N}} \sum_{m=1}^{N} \boldsymbol{F}\left(\boldsymbol{I}_{m}, V_{m}, \boldsymbol{\Phi}\right)^{2}} \\
f(I, V, \Phi)= & I_{p h}-I_{01}\left[\exp \left(\frac{V+I R_{s}}{a_{1} V_{t h}}\right)-1\right] \\
& -I_{\mathrm{O} 2}\left[\exp \left(\frac{V+I R_{s}}{a_{2} V_{t h}}\right)-1\right]-\left(\frac{V+I R_{s}}{R_{p}}\right)-I
\end{aligned}
$$

$\Phi=[I p h$, Io1, Io2, Rs, Rp, a1, a2] are the seven parameters of the PV module to be extracted. The aim of the extraction procedure is to minimize $\mathrm{f}$ with respect to $\Phi$

Iph is the cell-generated photocurrent

Io1 and Io2 are the reverse saturation currents of diode

1 and diode 2 , respectively.

Vth $(\mathrm{kT} / \mathrm{q})$ is the thermal voltage of the solar cell, $\mathrm{q}$ is the electron charge $(1.602176461019 \mathrm{C}), \mathrm{k}$ is the Boltzmann constant $(1.38065031023 \mathrm{~J} / \mathrm{K})$ and $\mathrm{T}$ is the temperature of the $\mathrm{p}-\mathrm{n}$ junction in Kelvin.

$\mathrm{Rs}$ and $\mathrm{Rp}$ are series and shunt resistance respectively

Variables a1 and $\mathrm{a} 2$ are the diode ideality constants; $\mathrm{a} 1$ and a2 represent the diffusion and recombination current component 


\subsection{The settings for Differential Evolution Algorithm} 40,000 .

The population size (NP), is chosen to be 70.The maximum generation number (Gmax) is set to

The mutation factor $(\mathrm{F})$ is set at 0.8 . The crossover rate $(\mathrm{CR})$ is chosen to be 1 .

\section{3 The settings for Genetic Algorithm}

Population type: Double Vector with Populations size $=20$, Fitness scaling: RankSelection function: Stochastic uniform Reproduction,Crossover fraction: 0.8,Mutation function: Adaptive Generations: 100

The initial search ranges for the parameters to be extracted given as upper bounds and lower bounds for the algorithms .

\begin{tabular}{|c|c|c|c|}
\hline S.No. & Parameter & $\begin{array}{c}\text { cMinimum } \\
\text { Value }\end{array}$ & $\begin{array}{c}\text { Maximum } \\
\text { Value }\end{array}$ \\
\hline 1 & Iph & 5.0 & 5.8 \\
\hline 2 & Io1 & $1 \mathrm{e}-6$ & $5 \mathrm{e}-6$ \\
\hline 3 & Io2 & 0 & $1 \mathrm{e}-6$ \\
\hline 4 & a1 & 1.2 & 2.0 \\
\hline 5 & a2 & 1.6 & 2.5 \\
\hline 6 & Rs & $4.8 \mathrm{e}-3$ & $5.5 \mathrm{e}-3$ \\
\hline 7 & Rp & 100 & 200 \\
\hline
\end{tabular}

\subsection{Genetic Algorithm execution plots}
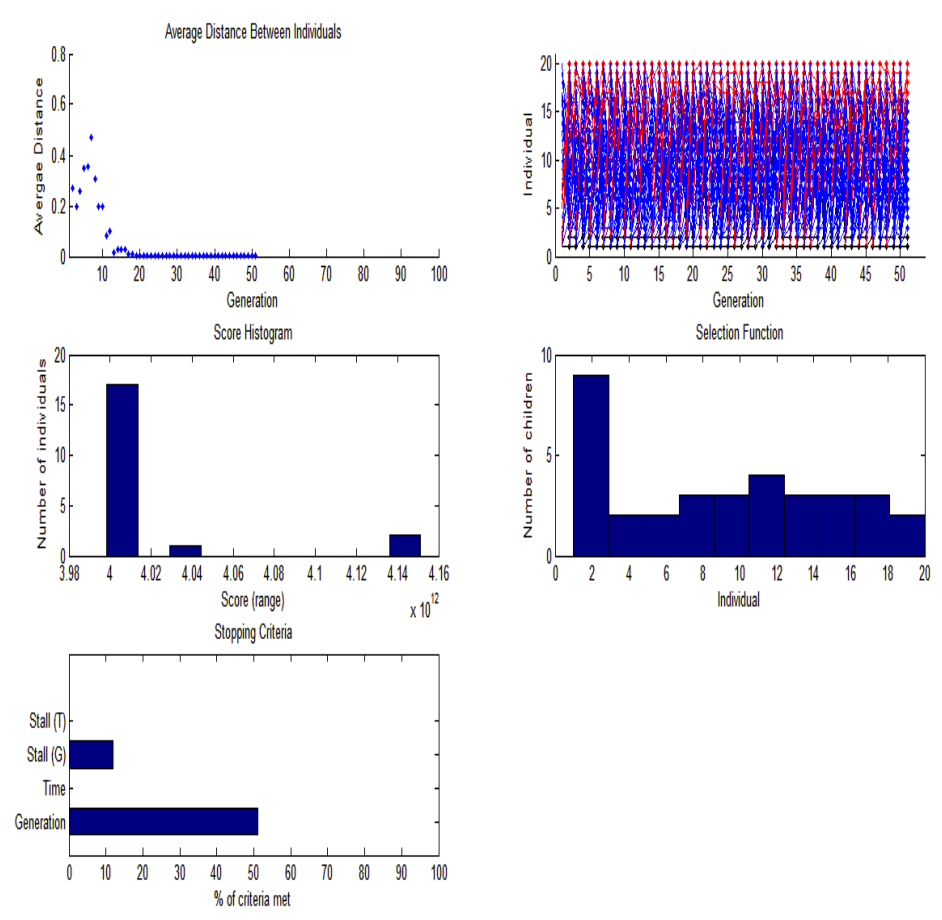


\subsection{Differntial Algorithm execution plots}
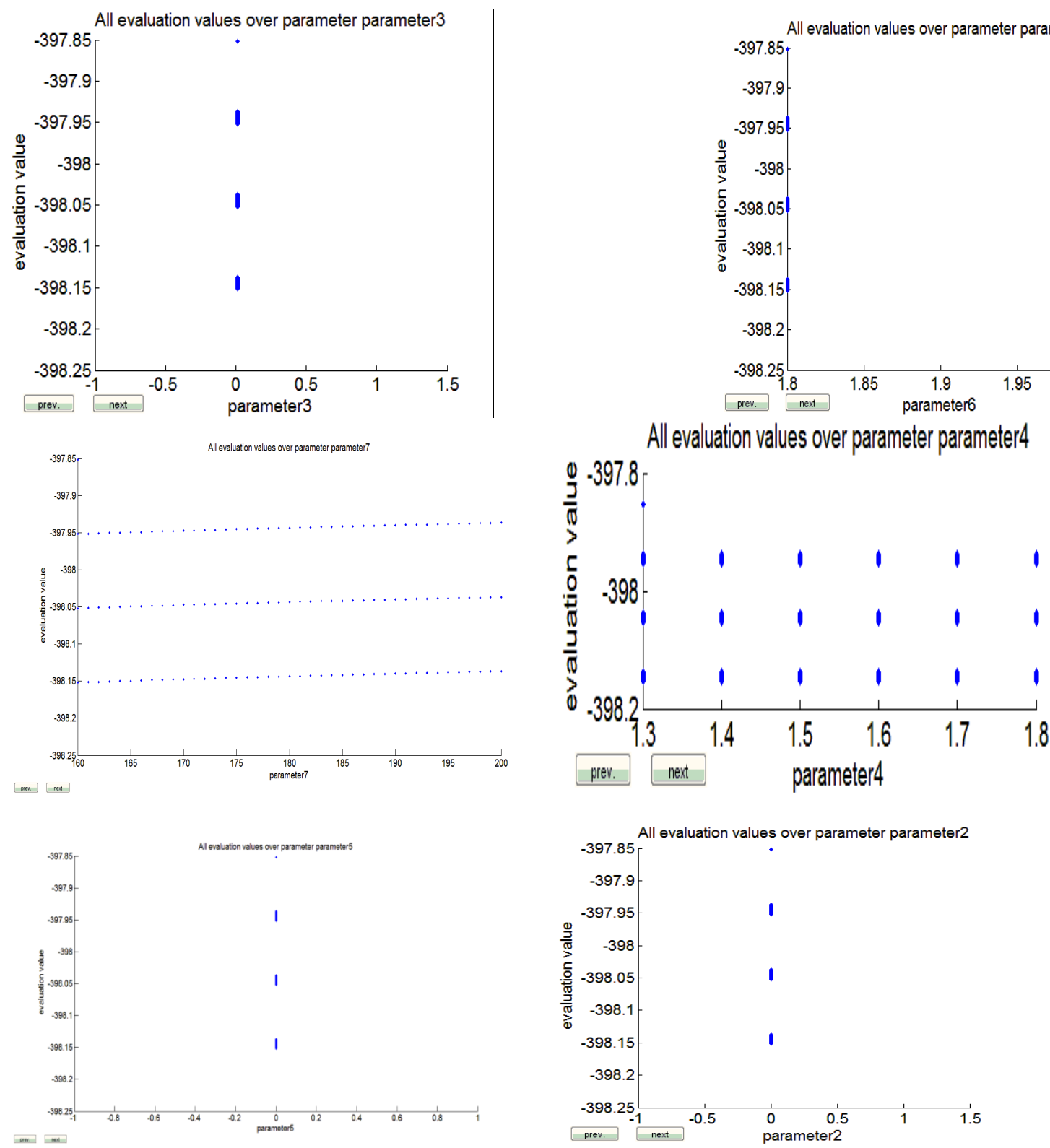

6.6 Tabulation of Extracted Values using Genetic Algorithm and differential evolution

\begin{tabular}{|c|c|c|c|c|}
\hline & Parameter & $\begin{array}{c}\text { Ideal } \\
\text { Value }\end{array}$ & $\begin{array}{c}\text { Value } \\
\text { Extracted } \\
\text { using GA }\end{array}$ & $\begin{array}{c}\text { Value } \\
\text { Extracted } \\
\text { Using DE }\end{array}$ \\
\hline 1 & Iph & 5.34 & 5.349 & 5.35 \\
\hline 2 & Io1 & $1 \mathrm{e}-6$ & 0.003 & 0.0025 \\
\hline 3 & Io2 & 0 & 0 & 0 \\
\hline 4 & a1 & 1.6 & 1.57 & 1.7 \\
\hline 5 & a2 & 2 & 1.92 & 1.9 \\
\hline 6 & Rs & $5.1 \mathrm{e}-3$ & 0.254 & 0.129 \\
\hline 7 & Rp & 160 & 162 & 160 \\
\hline
\end{tabular}




\section{Simulink model of pv module:}

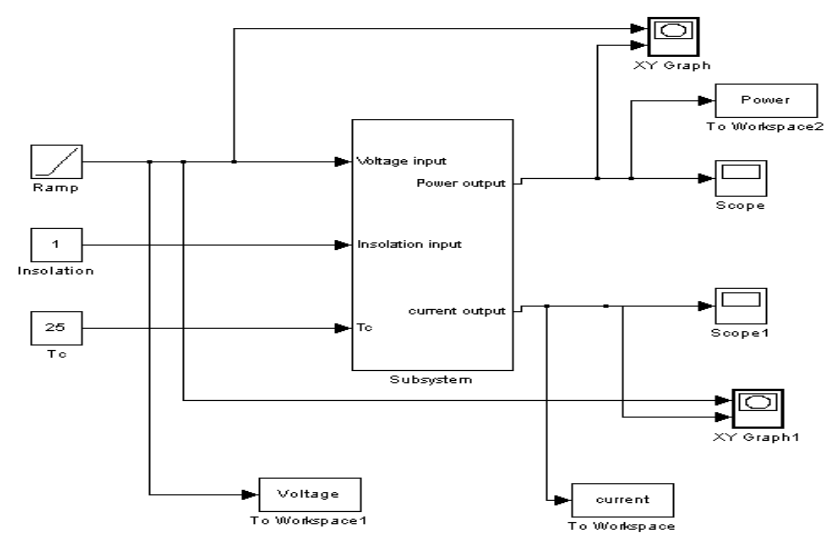

Fig ( 2) Simulink model of pv module

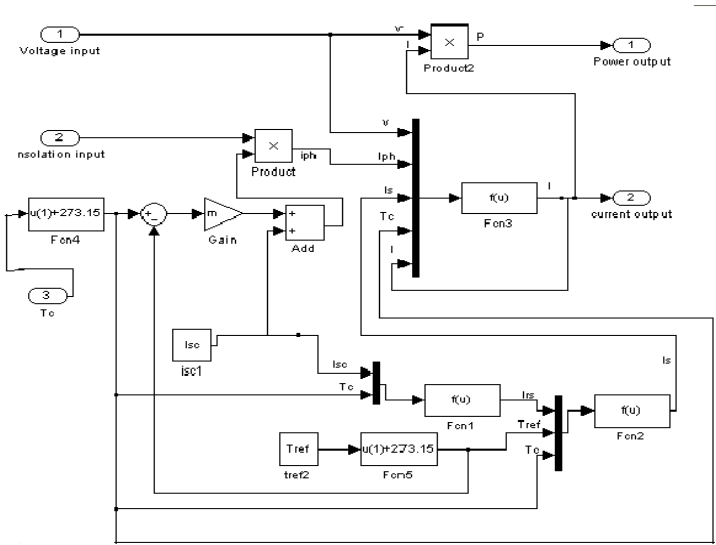

Fig( 3) Sub system implimented in PV model Table II Solarex MSX 60 Specifications $\left(1 \mathrm{~kW} / \mathrm{m}^{2}, 25^{\circ} \mathrm{C}\right)$

\begin{tabular}{|l|c|}
\hline \multicolumn{1}{|c|}{ Characteristics } & SPEC \\
\hline Typical peak power $\left(P_{p}\right)$ & $60 \mathrm{~W}$ \\
\hline Voltage at peak power $\left(V_{p p}\right)$ & $17.1 \mathrm{~V}$ \\
\hline Current at peak power $\left(I_{p p}\right)$ & $3.5 \mathrm{~A}$ \\
\hline Short-circuit current $\left(I_{S \mathrm{C}}\right)$ & $3.8 \mathrm{~A}$ \\
\hline Open-circuit voltage $\left(V_{\mathrm{OC}}\right)$ & $21.1 \mathrm{~V}$ \\
\hline Temperature coefficient of open-circuit voltage & $-73 \mathrm{mV} /{ }^{\circ} \mathrm{C}$ \\
\hline Temperature coefficient of short-circuit current $\left(K_{I}\right)$ & $3 \mathrm{~mA} /{ }^{\circ} \mathrm{C}$ \\
\hline Approximate effect of temperature on power & $-0.38 \mathrm{~W} /{ }^{\circ} \mathrm{C}$ \\
\hline Nominal operating cell temperature $($ NOCT $)$ & $49^{\circ} \mathrm{C}$ \\
\hline
\end{tabular}

\section{Results:}
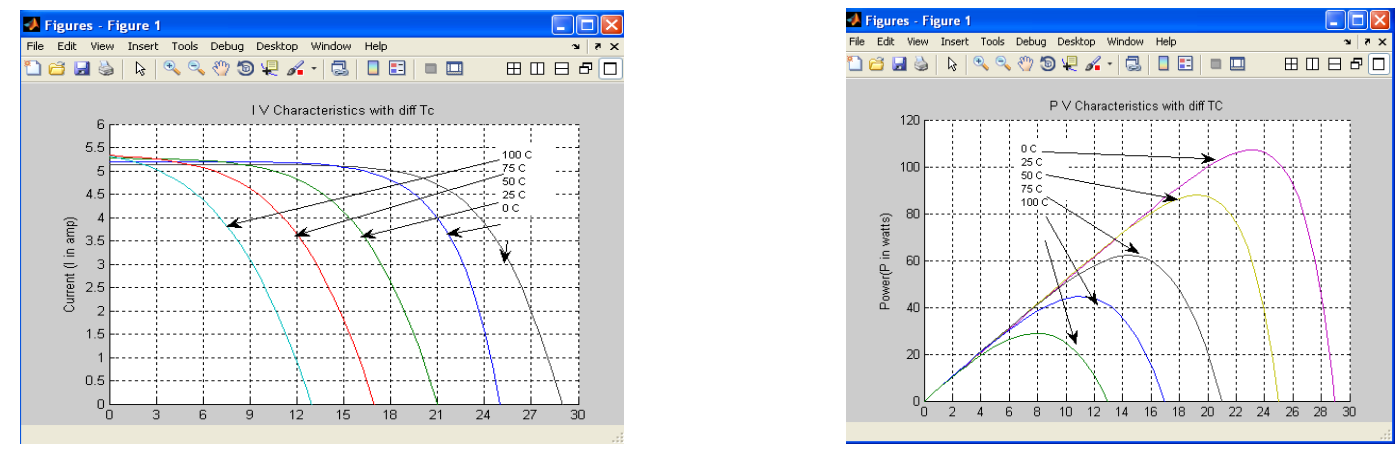

Fig ( 5) I-V Output charecterstics with different Tc Fig (6) P-V Output charecterstics with different Tc 


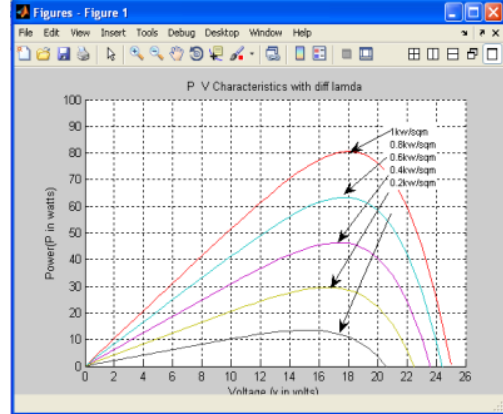

Fig ( 7) P-V Output charecterstics with different lamda lamda

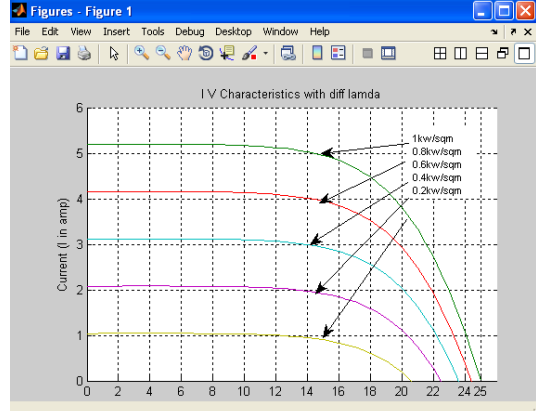

Fig ( 8) I-V Output charecterstics with different

\subsection{Pv Curve Characterstics Ga And De Of Solar Cell Module}

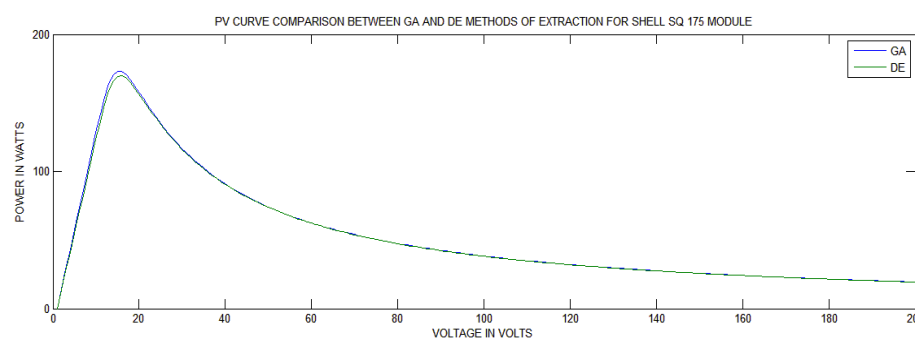

\section{Conclusions}

A PV model which is representative of the all PV cell, module, and array has been developed with Matlab/Simulink and been verified with a PV cell and a commercial module. The proposed model takes sunlight irradiance and cell temperature as input parameters and outputs the I-V and P-V characteristics under various conditions. A technique for improving the accuracy of the extracted values of solar cell parameters using genetic algorithms has-been implemented. It is based on formulating the parameter extraction problem as a search and optimization one. Since determination of the search range is of importance in applying this technique, one of the known extraction methods is to be used to determine approximate values for the solar cell parameters.

\section{References}

[1] S. W. Angrist, , Direct Energy Conversion, Allyn and Bacon, Inc., 4thedition, 1982, pp. 177-227.

[2] O. Wasynczuk, "Dynamic behavior of a class of photovoltaic power systems," IEEE Transactions on Power Apparatus and Systems, vol.PAS-102, no. 9, 1983, pp. 3031-3037.

[3] J. C. H. Phang, D. S. H. Chan, and J. R. Philips, "Accurate analytical method for the extraction of solar cell model parameters," Electronics Letters, vol. 20, no. 10, 1984, pp.406-408.

[4] C. C. Hua and C. M. Shen, "Study of maximum power tracking techniques and control of dc-de converters for photovoltaic powersystem,” Proceedings of 29th annual IEEE Power Electronics Specialists Conference, vol. 1, 1998, pp. 86-93.

[5] Phang J and Chan D 1986 A comparative study of extraction methods for solar cells I-V characteristics Solar Cells 18 1-12

[6] Araujo F, Sanchez E and Marti M 1982 Determination of the two-exponential solar cell equation parameters fromempirical data Solar Cells 5 199-204

[7] Lee J I, Brini J and Dimitriadis C A 1998 Simple parameter extraction method for non-ideal Schottky barrier diodes Electron. Lett. 34 1268-9

[8] Ouennoughi Z and Cheggar M 1999 A simpler method for extracting solar cell parameters using the conductance method Solid-State Electron. 43 1985-8[9] Werner J H 1988 Schottky barrier and pn-junction I-V plots, small signal evaluation Appl. Phys. A $47291-$ 300

[10] Lyakas M, Zaharia R and Eizenberg M 1995 Analysis ofnon-ideal Schottky and pn junction diodes, extraction of parameters from IV plots J. Appl. Phys. 78 5481-9

[11] Aubray V and Meyer F 1994 Schottky diodes with high series resistance: limitations of forward I-V methods J. Appl.Phys. 76 797384

[12] M. Veerachary, T. Senjyu, and K. Uezato, "Voltage-based maximum power point tracking control of PV system," IEEE Transactions onAerospace and Electronic Systems, vol. 38, no. 1, 2002, pp. 262-270.

[13] M. Veerachary and K.S. Shinoy, "V2-based power tracking for nonlinear PV sources," IEE Proceedings-Electric Power Applications,vol. 152, no. 5, 2005, pp. 1263-1270.

[14] I. S. Kim and M. J. Youn, "Variable-structure observer for solar array current estimation in a photovoltaic power-generation system," IEE Proceedings-Electric Power Applications, vol. 152, no. 4, 2005, pp.953-959.

15] I. S. Kim, M. B. Kim, and M. J. Youn, "New maximum power point tracker using sliding-mode observer for estimation of solar array current in the grid-connected photovoltaic system," IEEE Transaction on Industrial Electronics, vol. 53, no. 4, 2006, pp. 10271035.[12] K. H. Hussein, I. Muta, T. Hoshino, and M. Osakada, 
[16] J "Maximum photovoltaic power tracking: an algorithm for rapidly changing atmospheric conditions," IEE Proceedings of Generation, Transmission and Distribution, vol. 142, no. 1, 2005, pp. 953-959.

[17] Development of Generalized Photo voltaic Model Using MATLAB/SIMULINK Proceedings of the World Congress on Engineering and Computer Science 2008WCECS 2008, October 22 - 24, 2008, San Francisco, USA

[18] Solar cell parameter extraction using genetic algorithms @ 2001 IOP Publishing Ltd Printed in the UK

[19] Solar Cell Parameter Identification Using Genetic Algorithms Flavius-Maxim Petcuţ ${ }^{*}$, Toma Leonida-Dragomir**CEAI, Vol.12, No.1, pp. 30-37, 2010. 